\title{
$\beta$-hydroxyisovaleryl-shikonin induces human cervical cancer cell apoptosis via PI3K/AKT/mTOR signaling
}

\author{
DAN LU, JING QIAN, WEI LI, QIANQIAN FENG, SHU PAN and SIQUAN ZHANG \\ Department of Gynecology \& Obstetrics, College of Clinical Medicine, \\ Yangzhou University, Yangzhou, Jiangsu 225001, P.R. China
}

Received September 26, 2014; Accepted June 22, 2015

DOI: 10.3892/ol.2015.3769

\begin{abstract}
The present study aimed to investigate the inhibitory ability of $\beta$-hydroxyisovaleryl-shikonin ( $\beta$-HIVS) on the proliferation of human cervical cancer HeLa cells and to identify the mechanism of this effect. The HeLa cells were treated with $\beta$-HIVS and the inhibition of cell growth was detected by an MTT assay. Flow cytometry was performed to analyze the apoptosis rate and cell cycle distribution of HeLa cells. Reverse transcription-polymerase chain reaction and western blot analysis were used to examine the expression of the phosphatidylinositol 3-kinase (PI3K)/protein kinase B (AKT)/mammalian target of rapamycin (mTOR) signaling pathway proteins. The results revealed that $\beta$-HIVS inhibited HeLa cell proliferation in a dose- and time-dependent manner. With the administration of increasing concentrations of $\beta$-HIVS, the apoptotic rate of HeLa cells was also increased. The cell cycle was slightly arrested at the S phase, with $\sim 6 \%$ of cells in this phase, subsequent to treatment with $10 \mu \mathrm{M} \beta$-HIVS. In addition, $\beta$-HIVS markedly reduced the expression levels of PI3K, AKT, mTOR and 70-kDa ribosomal protein S6 kinase in HeLa cells. $\beta$-HIVS promoted cervical cancer cell apoptosis by inhibiting the PI3K/AKT/mTOR signaling pathway and suppressing downstream gene expression. The present study is expected to lead to the development of molecular targeted therapy for this signaling pathway as a novel method of cervical cancer treatment.
\end{abstract}

\section{Introduction}

Cervical cancer is a common malignant tumor, and according to the World Health Organization, 500,000 novel cases are

Correspondence to: Dr Dan Lu, Department of Gynecology \& Obstetrics, College of Clinical Medicine, Yangzhou University, Room 205, Building 2, 98 Nantong Western Road, Yangzhou, Jiangsu 225001, P.R. China

E-mail: ludan1968@126.com

Key words: $\beta$-hydroxyisovaleryl shikonin, cervical cancer, HeLa cells, phosphatidylinositol 3-kinase/protein kinase B/mammalian target of rapamycin signaling pathway, apoptosis diagnosed and 274,000 mortalities occur due to this cancer every year worldwide. In total, $83 \%$ of cases occur in developing countries, and are associated with a decreasing age of onset (1). Early stage cervical cancer may be treated by surgery. However, resection of progressive tumors, particularly recurrent or metastatic tumors, is considerably limited. Patients with late-stage cervical cancer exhibit a poor physical condition, which also limits the application of radiotherapy, chemotherapy or the two therapies combined $(2,3)$. The pathogenesis of cervical cancer is not yet completely understood, and there are currently no drugs available that may effectively control the occurrence and development of this cancer. Previous studies have indicated that the phosphatidylinositol 3-kinase (PI3K)/protein kinase B (AKT)/mammalian target of rapamycin (mTOR) signaling pathway regulates tumor cell proliferation, promotes cell cycle progression, participates in neovascularization and induces resistance to radiotherapy and chemotherapy in tumor cells (4-6). In addition, this signaling cascade is a major pathway in suppressing tumor cell apoptosis $(7,8)$. Cervical cancer may be treated by triggering tumor cell apoptosis through the combined application of radiotherapy and chemotherapy, which is a focus in the molecular-targeted therapy of cervical cancer (9).

Shikonin, a naphthoquinone derivative, is a naturally occurring active chemical that is found in the root of Lithospermum erythrorhizon. Shikonin has been reported to demonstrate anti-cancer, anti-inflammation, anti-human immunodeficiency virus and anti-fungal activity $(10,11)$. Shikonin demonstrates strong toxicity, but does not exhibit tumor specificity, and therefore, shikonin has not been widely used in the clinic (12). Previous studies of the extraction or synthesis of high-performance non-toxic shikonin derivatives has received considerable attention (13-15). $\beta$-hydroxyisovaleryl-shikonin ( $\beta$-HIVS) is a natural shikonin derivative (16). The present study investigated the inhibitory effect of $\beta$-HIVS on the proliferation of human cervical cancer HeLa cells, and explored the molecular mechanism of action of the PI3K/AKT/mTOR signaling pathway on $\beta$-HIVS-induced apoptosis of HeLa cells.

\section{Materials and methods}

Reagents and equipment. HeLa human cervical cancer cells were purchased from China Center for Type Culture 
Collection (Wuhan University, Wuhan, Hubei, China). Fetal bovine serum was obtained from Hangzhou Sijiqing Biological Engineering Materials Co. Ltd. (Hangzhou, Zhejiang, China) and high-glucose Dulbecco's modified Eagle's medium was purchased from Gibco Life Technologies (Carlsbad, CA, USA). $\beta$-HIVS (>98\% purity) was purchased from Wako Pure Chemical Industries, Ltd. (Saitama, Japan). MTT was purchased from Sigma-Aldrich (St. Louis, MO, USA) and dimethyl sulfoxide was purchased from Meilian Biological Technology Co., Ltd. (Shanghai, China). Acridine orange/ethidium bromide double fluorescence kit was obtained from Nanjing KeyGen Biotech Co., Ltd. (Nanjing, Jiangsu, China), Annexin V-fluorescein isothiocyanate (FITC)/propidium iodide apoptosis kit was obtained from Roche (Basel, Switzerland) and the flow cytometer used was obtained from BD Biosciences (Franklin Lakes, NJ, USA). Rabbit anti-human PI3K, AKT and 70-kDa ribosomal protein S6 kinase $\left(\mathrm{P}^{2} 0^{\mathrm{S} 6 \mathrm{~K}}\right)$ antibodies, and the mouse anti-human mTOR antibody were purchased from Cell Signaling Technology (Danvers, MA, USA). The rabbit anti-human $\beta$-actin polyclonal antibody was purchased from Beijing Zhongshan Golden Bridge Biotechnology Co., Ltd. (Beijing, China). The study protocol complied with all committee regulations approved by the Ethics Committee for Experimentation of Yangzhou University (Yangzhou, China).

Cell culture. Human cervical cancer HeLa cells were maintained in high-glucose Dulbecco's modified Eagle's medium supplemented with $10 \%$ fetal bovine serum, and were incubated in a $37^{\circ} \mathrm{C}$ incubator with a $5 \% \mathrm{CO}_{2}$ atmosphere, under saturated humidity (2406-2 $\mathrm{CO}_{2}$ incubator; Heraeus, Hanau, Germany). A high pressure sterilization autoclave (ES 315; Tomy Company, Ltd., Tokyo, Japan was used to prepare the phosphate-buffered saline (PBS) buffer solution for cell passage cultivation. The cells were passaged with $0.25 \%$ trypsin (Nanjing KeyGen Biotech Co., Ltd.). The cells used in the present study were in the logarithmic phase of growth at $24 \mathrm{~h}$ subsequent to incubation. $\beta$-HIVS $(2.3 \mathrm{mg})$ was dissolved in dimethyl sulfoxide $(592 \mu \mathrm{l})$ and the product $(10 \mathrm{mM})$ was stored at $-20^{\circ} \mathrm{C}$ prior to use. A thermostatic bath (W201B; Senco Technology Co., Ltd., Shanghai, China) was used to rewarm the frozen cell solutions.

Proliferation assay. The HeLa cells were seeded at a density of $1 \times 10^{5}$ cells $/ \mathrm{ml}$ onto a 96 -well plate, with $100 \mu 1$ of cell suspension being added to each well. The cells were then incubated at $37^{\circ} \mathrm{C}$ for $24 \mathrm{~h}$. The treatment groups consisted of a blank zero group that contained no incubated cells, a control group that only contained an equal volume of solvent and an experimental group. Prior to the current experiment, cells were treated $0,2.5,5,10,20,40,80$ and $160 \mu \mathrm{M} \beta$-HIVS to identify an optimum dose range. Cells were obviously apoptotic with increasing concentrations of $\beta$-HIVS, particularly at concentrations $>40 \mu \mathrm{M}$. Therefore, the experimental group was treated with final concentrations of 1.56, 3.13, $6.25,12.50$ and $25.00 \mu \mathrm{M} \beta$-HIVS in triplicate to determine the effective and safe concentration of $\beta$-HIVS. Subsequent to incubation at $37^{\circ} \mathrm{C}$ for 24,48 or $72 \mathrm{~h}, 5 \mathrm{mg} / \mathrm{ml} \mathrm{MTT}$ was added to each well and the wells were incubated for $4 \mathrm{~h}$. The supernatant was discarded and $150 \mu \mathrm{l}$ dimethyl sulfoxide was added to each well prior to the wells being vortexed for $10 \mathrm{~min}$. When the crystal had completely dissolved, the absorbance values were measured at $490 \mathrm{~nm}$ using a microplate reader (680; Bio-Rad Laboratories, Inc., Hercules, CA, USA). The toxicity exerted by $\beta$-HIVS on tumor cell proliferation was determined by the inhibitory rate. The inhibitory rate was calculated as follows: Inhibitory rate $(\%)=$ (absorbance of the control group - absorbance of the experimental group) / absorbance of the control group x 100. The experiment was independently performed in triplicate.

\section{Detection of apoptosis}

Acridine orangelethidium bromide double fluorescence staining to detect morphological changes in apoptotic cells. The HeLa cells were seeded at a density of $4 \times 10^{5}$ cells $/ \mathrm{ml}$ in six-well plates, at a total volume of $1 \mathrm{ml} /$ well, and the cells were then incubated for $24 \mathrm{~h}$. The HeLa cells were treated with $\beta$-HIVS at final concentrations of $0,1,5$ and $10 \mu \mathrm{M}$ for 24 or $48 \mathrm{~h}$, and then treated with $0.25 \%$ trypsin, washed twice with PBS and a $6 \times 10^{6}$ cell $/ \mathrm{ml}$ suspension was prepared. Subsequently, $25 \mu \mathrm{l}$ of cell suspension was combined with $1 \mu \mathrm{l}$ acridine orange/ethidium bromide dye and added to a clean slide. Cell morphology was then observed and images were captured under an inverted fluorescence microscope (TS-100; Nikon Corporation, Tokyo, Japan) at a wavelength of $510 \mathrm{~nm}$. The control group acted as the normal cell culture group.

Annexin V-FITC/propidium iodide double staining and flow cytometry to determine the apoptotic rate. The HeLa cells were seeded at a density of $4 \times 10^{5}$ cells/well onto six-well plates, incubated for $24 \mathrm{~h}$, and then treated with $0,1,5$ and $10 \mu \mathrm{M}$ $\beta$-HIVS in triplicate. At $48 \mathrm{~h}$, the cells were harvested and a single cell suspension was prepared for each treatment group. The control group acted as the normal cell culture group. The single cell suspension was washed with $1 \mathrm{ml}$ pre-cooled PBS at $4^{\circ} \mathrm{C}$ and centrifuged at $100 \mathrm{x} \mathrm{g}$ for $10 \mathrm{~min}$ (5810R; Eppendorf, Hamburg, Germany). The supernatant was discarded and the procedure was repeated twice. Then, $100 \mu \mathrm{l}$ of binding buffer and $5 \mu \mathrm{l}$ of Annexin V-FITC was added and the cells were incubated in the dark for $30 \mathrm{~min}$ at room temperature. Next, $5 \mu \mathrm{l}$ propidium iodide was added in the dark for $5 \mathrm{~min}$. The samples were quantitatively detected using a FACScan flow cytometer. Cells without FITC-labeled Annexin V and propidium iodide were considered as negative controls. The results were analyzed using Cell Quest Software.

Flow cytometry analysis of cell cycle distribution. The HeLa cells were seeded at a density of $4 \times 10^{5}$ cells/well, incubated for $24 \mathrm{~h}$ and then treated with $0,1,5$ and $10 \mu \mathrm{M} \beta$-HIVS in triplicate. Subsequent to $48 \mathrm{~h}$, the cells were harvested and made into single cell suspensions for each treatment group. The control group acted as the normal cell culture group. The cells were fixed in $70 \%$ cold ethanol at $4^{\circ} \mathrm{C}$ overnight, and then the cell suspensions were centrifuged and the fixative was removed. Following 2 washes with PBS, the samples were treated with propidium iodide and RNase A for $30 \mathrm{~min}$ at $37^{\circ} \mathrm{C}$ at a final concentration of $50 \mu \mathrm{M}$. The cell cycle distribution was measured using a flow cytometer.

Reverse transcription-PCR. At $48 \mathrm{~h}$ subsequent to the treatment of HeLa cells with $0,1,5$ and $10 \mu \mathrm{M} \beta$-HIVS, total RNA was 
Table I. Effect of $\beta$-HIVS on HeLa cell proliferation at various time points.

\begin{tabular}{lccr}
\hline & \multicolumn{2}{c}{ Inhibitory rate, $\%$} \\
\cline { 2 - 4 } $\begin{array}{l}\text { Concentration } \\
\text { of } \beta \text {-HIVS, } \mu \mathrm{M}\end{array}$ & $24 \mathrm{~h}$ & $48 \mathrm{~h}$ & 0.00 \\
\hline Control & 0.00 & 0.00 & $79.84 \pm 5.02^{\mathrm{a}, \mathrm{b}}$ \\
1.56 & $36.53 \pm 2.99^{\mathrm{a}}$ & $41.12 \pm 0.75^{\mathrm{a}}$ & $86.53 \pm 3.31^{\mathrm{a}, \mathrm{b}}$ \\
3.13 & $60.30 \pm 3.35^{\mathrm{a}}$ & $64.58 \pm 0.61^{\mathrm{a}}$ & $90.92 \pm 0.72^{\mathrm{a}, \mathrm{b}}$ \\
6.25 & $81.15 \pm 1.77^{\mathrm{a}}$ & $82.49 \pm 1.36^{\mathrm{a}}$ & $94.46 \pm 0.45^{\mathrm{a}, \mathrm{b}}$ \\
12.50 & $87.12 \pm 2.15^{\mathrm{a}}$ & $88.55 \pm 0.33^{\mathrm{a}}$ & $98.29 \pm 0.39^{\mathrm{a}, \mathrm{b}}$ \\
25.00 & $89.11 \pm 3.67^{\mathrm{a}}$ & $95.97 \pm 0.19^{\mathrm{a}, \mathrm{b}}$ &
\end{tabular}

${ }^{\mathrm{a}} \mathrm{P}<0.001$ vs. control group at the same time point; ${ }^{\mathrm{b}} \mathrm{P}<0.01 \mathrm{vs.} 24 \mathrm{~h}$ at the same concentration. $\beta$-HIVS, $\beta$-hydroxyisovaleryl-shikonin.

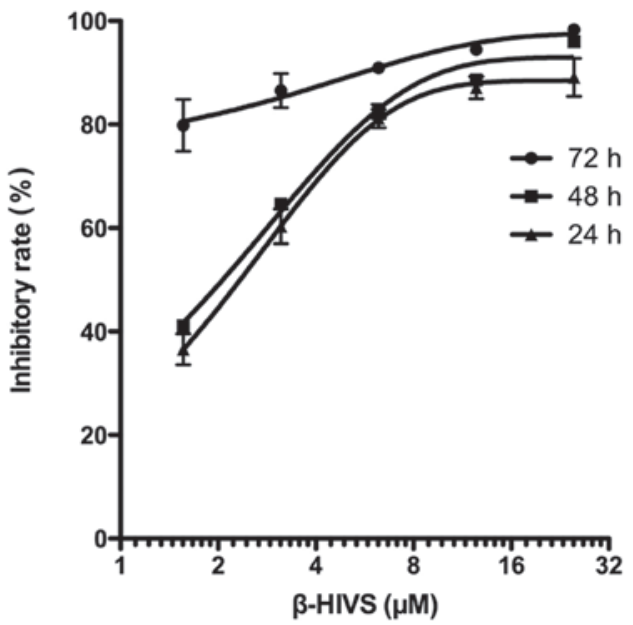

Figure 1. Inhibitory rate of HeLa cell proliferation at various time points subsequent to treatment with $\beta$-HIVS. $\beta$-HIVS, $\beta$-hydroxyisovaleryl-shikonin.

extracted using the one-step TRIzol method (Invitrogen Life Technologies, Inc., Carlsbad, CA, USA). The concentration and purity of RNA was determined using ultraviolet spectroscopy. The ratio of the absorbance value at $260 \mathrm{~nm}$ to the absorbance value at $280 \mathrm{~nm}$ was between 1.6 and 1.8. The extracted total RNA was stored at $-80^{\circ} \mathrm{C}$ prior to use or immediately reverse-transcribed into cDNA. Primers for real-time quantitative PCR were synthesized by Takara Bio, Inc. (Otsu, Shiga, Japan), according to the relevant accession number in PubMed. The primer sequences were as follows: $P I 3 K$ upstream, 5'-CTGTCAATCGGTGACTGTGTGG-3' and downstream, 5'-AAACAGGTCAATGGCTGCATCATA-3' (177 bp); AKT upstream, 5'-CTTGCTTTCAGGGCTGCTCA-3' and downstream, 5'-CTTGCTTTCAGGGCTGCTCA-3' (117 bp); MTOR upstream, 5'-AGAAACTGCACGTCAGCA CCA-3' and downstream, 5'-CCATTCCAGCCAGTCATC TTTG-3' (83 bp); and P70S6K upstream, 5'-CTCAGTGAAAGT GCCAATCAGGTC-3' and downstream, 5'-GCTGCCAAT AAATCTTCGAGGTG-3' (126 bp). Reverse transcription was performed using the PrimeScript RT reagent kit (catalog no., RR037A; Takara Bio, Inc.) in a thermal cycler (2720; Applied Biosystems, Inc., Foster City, CA, USA). GAPDH acted as an internal reference. Quantitative PCR was performed using SYBR Premix Ex Taq II (catalog no., RR820A; Takara Bio,
Inc.) and analyzed using a 7500 Real-Time PCR System (Life Technologies, Grand Island, NY, USA). The results were compared with the results of the GAPDH internal reference.

Western blotting. The HeLa cells were treated for $48 \mathrm{~h}$ with 0 , 1,5 and $10 \mu \mathrm{M} \beta$-HIVS and lysed. The protein concentration was measured using a Coomassie Brilliant Blue assay (Beyotime Institute of Biotechnology, Shanghai, China). Protein was isolated using $10 \%$ sodium dodecyl sulfate-polyacrylamide gel electrophoresis (MiniPROTEAN ${ }^{\circledR} 3$ Electrophoresis System; Bio-Rad Laboratories, Inc.) and the bands were subseqeuntly transferred onto a polyvinylidene difluoride membrane. The membrane was blocked with Tris-buffered saline containing $50 \mathrm{mg} / \mathrm{l}$ skim milk for $1 \mathrm{~h}$ at room temperature, and then incubated with primary antibody (dilution, 1:1,000) at $4^{\circ} \mathrm{C}$ overnight. The membrane was then washed three times, incubated with secondary horseradish peroxidase-labeled IgG antibody (dilution, 1:5,000) for $1 \mathrm{~h}$ at room temperature and washed an additional three times. The blots were developed using the chemiluminescence LumiGLO reagent (Cell Signaling Technology), photosensitized in a G:BOX gel imaging system (Syngene, Cambridge, UK), visualized and fixed. Each experiment was performed in triplicate. The bands were analyzed using Image J analysis software (National Institutes of Health, Bethesda, MA, USA), and the grayscale values were measured. $\beta$-actin was used as an internal reference. The relative quantity of protein was calculated as the ratio of the grayscale values of PI3K, AKT, mTOR and P70 ${ }^{\text {S6K }}$ to $\beta$-actin.

Statistical analysis. All data were expressed as the mean \pm standard deviation. Intergroup data were analyzed using an independent samples $t$-test or Wilcoxon rank-sum test. The differences between the dosing and time-point groups were compared using one-way analysis of variance. Paired comparisons were performed between each dosing group. $\mathrm{P}<0.05$ was considered to indicate a statistically significant difference.

\section{Results}

Effect of $\beta$-HIVS on HeLa cell proliferation. As shown in Table I and Fig. 1, the results of the MTT assay revealed that the inhibitory rate of HeLa cell proliferation was gradually 
Table II. Effect of $\beta$-HIVS on the apoptotic rate and cell cycle distribution of HeLa cells.

\begin{tabular}{lcccc}
\hline \multirow{2}{*}{$\begin{array}{c}\text { Concentration } \\
\text { of } \beta \text {-HIVS, } \mu \mathrm{M}\end{array}$} & Apoptotic rate, $\%$ & $\mathrm{G}_{0} / \mathrm{G}_{1}$ phase & S phase & $\mathrm{G}_{2} / \mathrm{M}$ phase \\
\hline Control & $5.68 \pm 0.55$ & $69.89 \pm 2.33$ & $19.24 \pm 0.33$ & $10.88 \pm 2.00$ \\
1 & $6.50 \pm 0.32$ & $68.55 \pm 0.45$ & $19.35 \pm 0.17$ & $12.10 \pm 0.28$ \\
5 & $8.93 \pm 1.66$ & $66.66 \pm 0.84$ & $21.34 \pm 1.04$ & $11.99 \pm 0.20$ \\
10 & $15.77 \pm 0.37^{\mathrm{a}}$ & $60.36 \pm 0.86^{\mathrm{a}}$ & $27.30 \pm 2.05^{\mathrm{a}}$ & $12.34 \pm 1.19^{\mathrm{a}}$ \\
\hline
\end{tabular}

Data are presented as the mean \pm standard deviation. ${ }^{\text {a }}<0.001$ vs. control group. $\beta$-HIVS, $\beta$-hydroxyisovaleryl-shikonin.
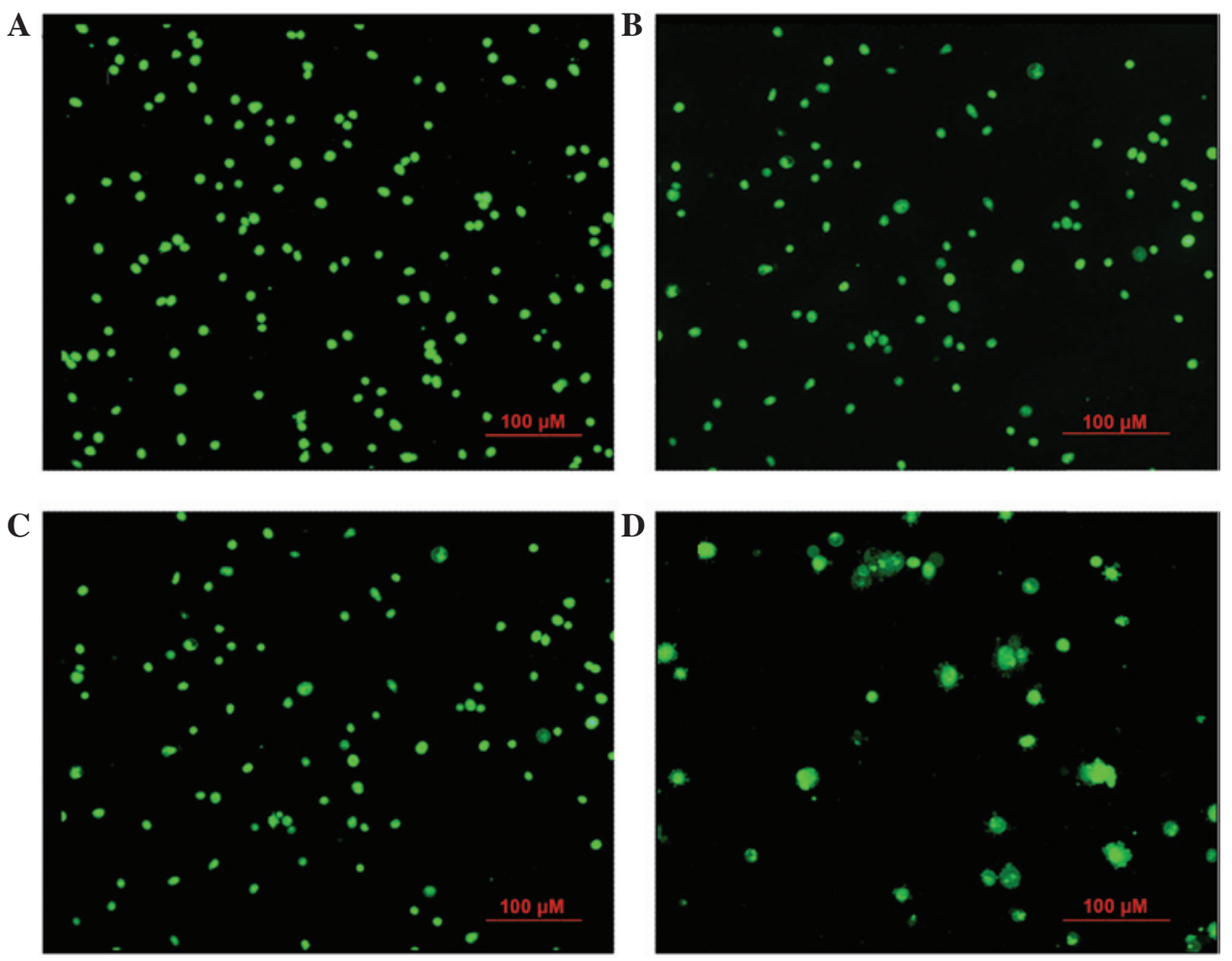

Figure 2. Acridine orange/ethidium bromide staining for morphological changes in apoptotic HeLa cells at $24 \mathrm{~h}$ in the (A) control group and cells treated with (B) $1 \mu \mathrm{M} \beta$-HIVS, (C) $5 \mu \mathrm{M} \beta$-HIVS and (D) $10 \mu \mathrm{M} \beta$-HIVS. Magnification, x100. $\beta$-HIVS, $\beta$-hydroxyisovaleryl-shikonin.

and significantly upregulated with the increased concentration of $\beta$-HIVS at the same time point compared with the control group $(\mathrm{P}<0.001)$. The rate of the inhibition of HeLa cell proliferation gradually increased with time at the same $\beta$-HIVS concentration, and a statistically significant difference was detected between the 24-h group and the 72-h group $(\mathrm{P}<0.01)$. However, no statistically significant difference was identified between the 24 and $48 \mathrm{~h}$ treatment groups $(\mathrm{P}>0.05)$. These results indicated that $\beta$-HIVS suppressed HeLa cell proliferation in a time- and dose-dependent manner. At 24, 48 and $72 \mathrm{~h}$ subsequent to $\beta$-HIVS treatment, the half maximal inhibitory concentrations $\left(\mathrm{IC}_{50}\right)$ of $\beta$-HIVS were $2.24,2.04$ and $0.23 \mu \mathrm{M}$, respectively.

Morphological changes in apoptotic HeLa cells induced by $\beta$-HIVS. At $24 \mathrm{~h}$ subsequent to $\beta$-HIVS treatment, cells in the control group appeared rounded with green-stained nuclei of uniform size. With increasing concentrations of $\beta$-HIVS, the number and structure of apoptotic HeLa cells became evidently altered. Subsequent to treatment with $1 \mu \mathrm{M} \beta$-HIVS, pyknosis appeared. At a concentration of $5 \mu \mathrm{M} \beta$-HIVS, the cell shape was irregular and certain cells exhibited early apoptotic changes, including chromatin condensation, massive chromatin, pyknosis and crescent-shaped cells. At a concentration of $10 \mu \mathrm{M} \beta$-HIVS, the cell morphology was evidently altered and the proportion of apoptotic cells had increased. Late apoptotic changes were visible, including chromatin condensation, nuclear fragmentation, punctiform or lobulated nuclei of various sizes, intact membrane and membrane blebbing, with the presence of programmed cell death being identified (Fig. 2).

Effect of $\beta$-HIVS on the apoptotic rate and cell cycle of HeLa cells. Treatment with $\beta$-HIVS promoted apoptosis in HeLa cells. At $48 \mathrm{~h}$ subsequent to treatment with 1, 5 and $10 \mu \mathrm{M} \beta$-HIVS, 
A

FACSDiva version 6.1.2

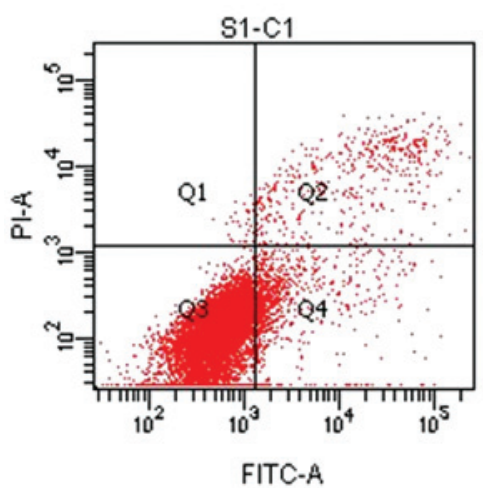

C

FACSDiva version 6.1.2

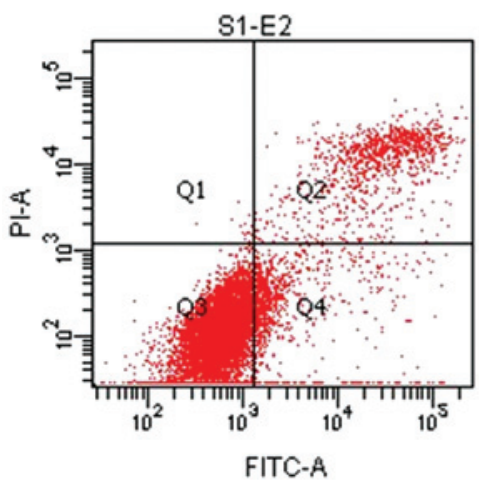

B

FACSDiva version 6.1.2

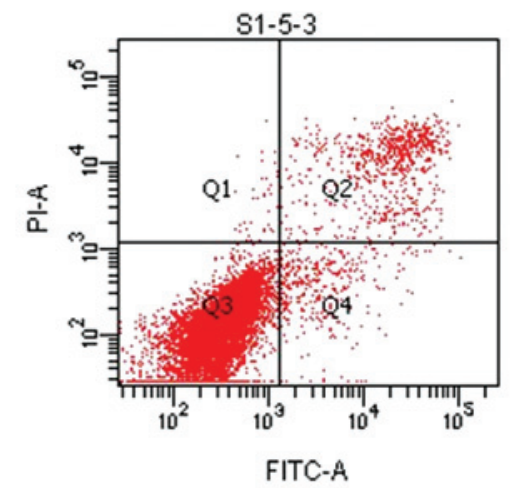

D FACSDiva version 6.1.2

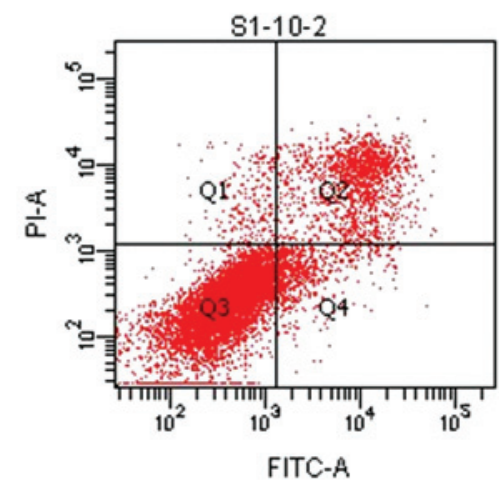

Figure 3. Annexin/propidium iodide staining to determine the apoptotic rate of HeLa cells subsequent to treatment with $\beta$-HIVS in the (A) control group and cells treated with (B) $1 \mu \mathrm{M} \beta$-HIVS, (C) $5 \mu \mathrm{M} \beta$-HIVS and (D) $10 \mu \mathrm{M} \beta$-HIVS. Left upper quadrant, necrotic cells, due to mechanical injury; left lower quadrant, normal cells; right upper quadrant, late apoptotic cells; right lower quadrant, early apoptotic cells. $\beta$-HIVS, $\beta$-hydroxyisovaleryl-shikonin.

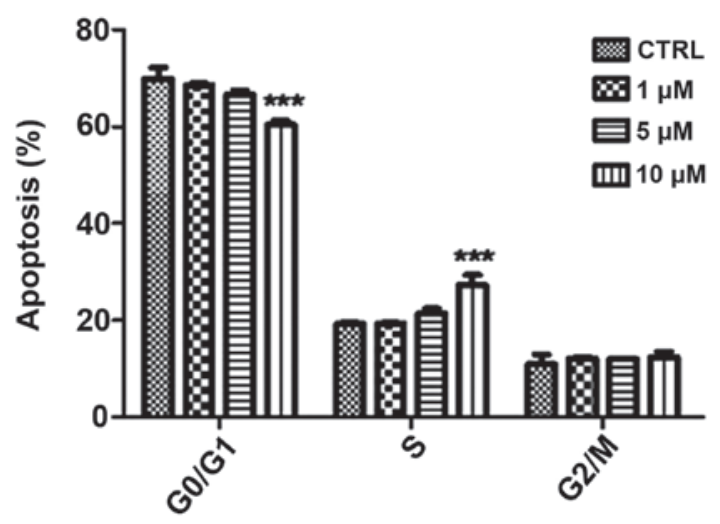

Figure 4. Flow cytometric analysis of the effects of $\beta$-HIVS on the cell cycle distribution of HeLa cells. ${ }^{* * *} \mathrm{P}<0.001$ vs. control group. $\beta$-HIVS, $\beta$-hydroxyisovaleryl-shikonin; CTRL, control.

the apoptotic rates were $6.50,8.93$ and $15.77 \%$, respectively. Compared with the control group, which demonstrated an apoptotic rate of $5.68 \%$, the apoptotic rate was significantly higher in the group treated with $10 \mu \mathrm{M} \beta$-HIVS $(15.77 \%$; $\mathrm{P}<0.001)$. However, no statistically significant difference in the apoptotic rate was determined between the cells treated with 1 and $5 \mu \mathrm{M} \beta$-HIVS $(\mathrm{P}>0.05)$. $\beta$-HIVS-induced apoptosis appeared to be dose-dependent, as the number of early apoptotic, late apoptotic and necrotic cells gradually increased with increased concentrations of $\beta$-HIVS. Cell cycle analysis revealed that treatment with various concentrations of $\beta$-HIVS led to alterations in HeLa cell cycle distribution. The number of cells in the $\mathrm{G}_{0} / \mathrm{G}_{1}$ phase decreased and the number of cells in the $\mathrm{S}$ phase increased, but the number of cells in the $\mathrm{G}_{2} / \mathrm{M}$ phase did not evidently alter. Cell cycle blockade occurred in the $S$ phase. Subsequent to the treatment of HeLa cells with $10 \mu \mathrm{M} \beta$-HIVS for $48 \mathrm{~h}$, statistically significant differences in the number of cells in the $\mathrm{G}_{0} / \mathrm{G}_{1}, \mathrm{~S}$ and $\mathrm{G}_{2} / \mathrm{M}$ phases were observed between the $\beta$-HIVS-treated groups and the control group $(\mathrm{P}<0.001$; Table II; Figs. 3 and 4).

Effect of $\beta$-HIVS on PI3K, AKT, mTOR and P70 S6K $m R N A$ expression. Treatment with 1,5 and $10 \mu \mathrm{M} \beta$-HIVS resulted in time- and concentration-dependent effects on the expression levels of PI3K, AKT, mTOR and P70 ${ }^{\mathrm{S} 6 \mathrm{~K}}$ mRNA in HeLa cells. At $48 \mathrm{~h}$ subsequent to treatment with $\beta$-HIVS, the expression of PI3K, AKT, mTOR and P70 ${ }^{\mathrm{S} 6 \mathrm{~K}} \mathrm{mRNA}$ was significantly reduced. Compared with the control group, the expression of $\mathrm{PI} 3 \mathrm{~K}$ in the $10 \mu \mathrm{M} \beta$-HIVS group, AKT in the 1,5 and $10 \mu \mathrm{M}$ $\beta$-HIVS groups, mTOR in the 1,5 and $10 \mu \mathrm{M} \beta$-HIVS groups and $\mathrm{P} 70^{\mathrm{S} 6 \mathrm{~K}}$ in the 1,5 and $10 \mu \mathrm{M} \beta$-HIVS groups was significantly decreased $(\mathrm{P}<0.05$; Fig. 5$)$.

Effect of $\beta$-HIVS on PI3K, AKT, mTOR and P70 ${ }^{56 K}$ protein expression. The results of western blot analysis revealed that at $48 \mathrm{~h}$ subsequent to treatment with 1, 5 and $10 \mu \mathrm{M} \beta$-HIVS, 

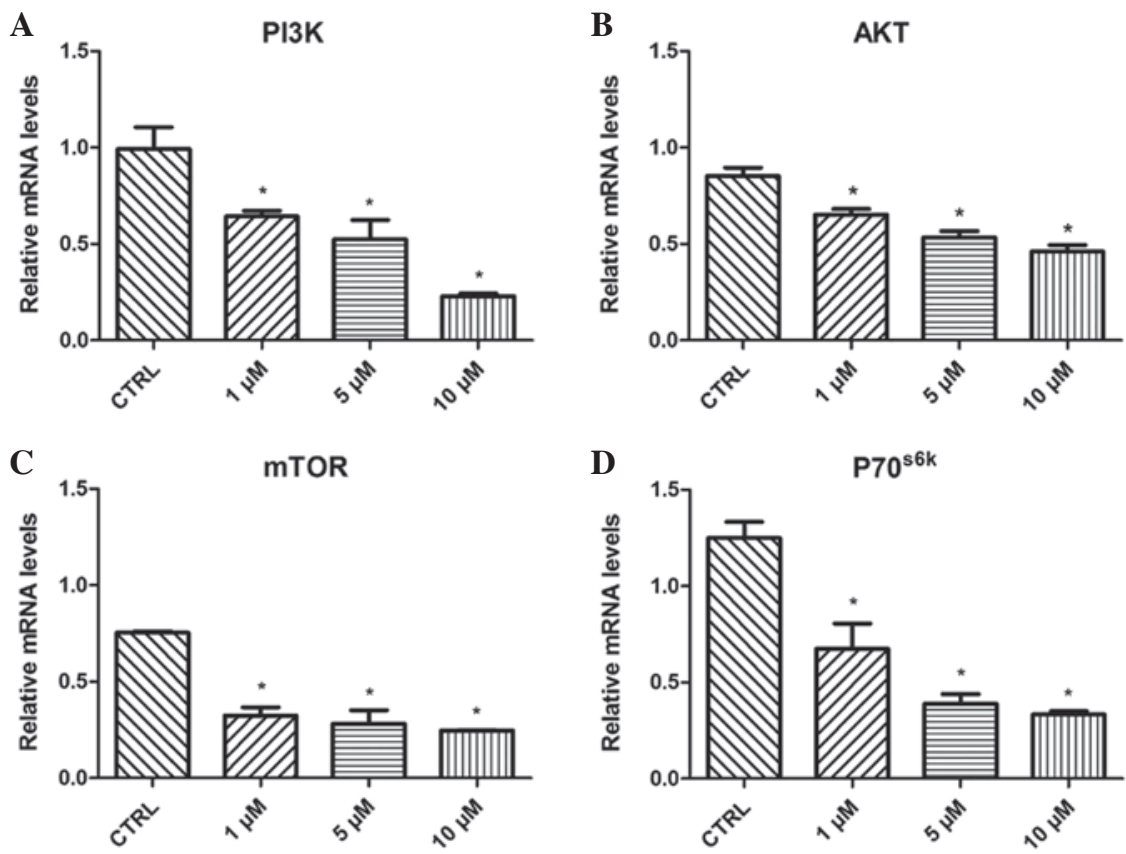

Figure 5. Effect of $\beta$-HIVS treatment on (A) PI3K, (B) AKT, (C) mTOR and (D) P70 ${ }^{\mathrm{S} 6 \mathrm{~K}}$ mRNA expression in HeLa cells. " $\mathrm{P}<0.05$ vs. control group. $\beta$-HIVS, $\beta$-hydroxyisovaleryl-shikonin; PI3K, phosphatidylinositol 3-kinase; AKT, protein kinase B; mTOR, mammalian target of rapamycin; P70 ${ }^{\mathrm{s} 6 \mathrm{~K}}$, 70-kDa ribosomal protein S6 kinase; CTRL, control.

A

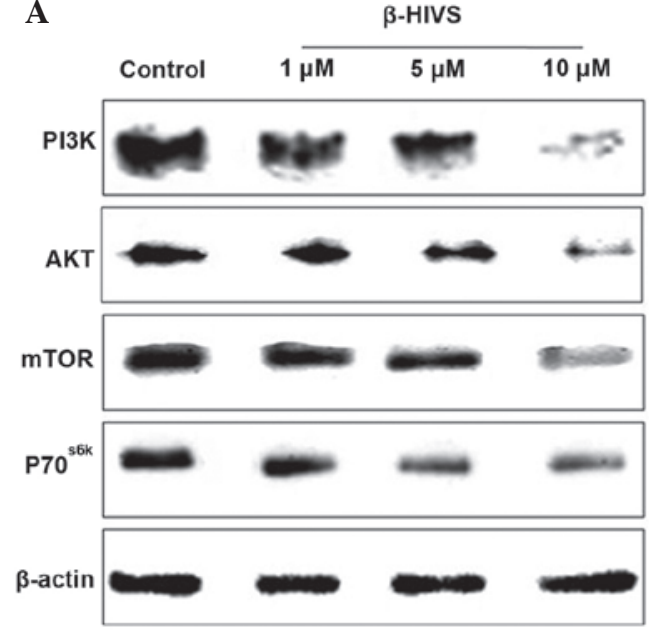

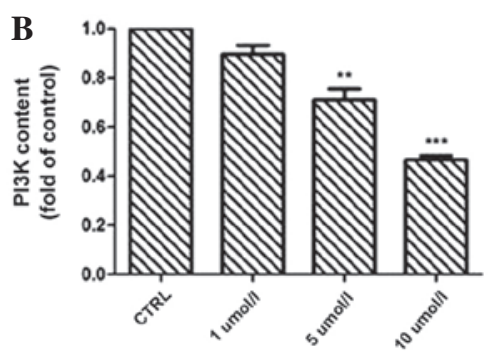

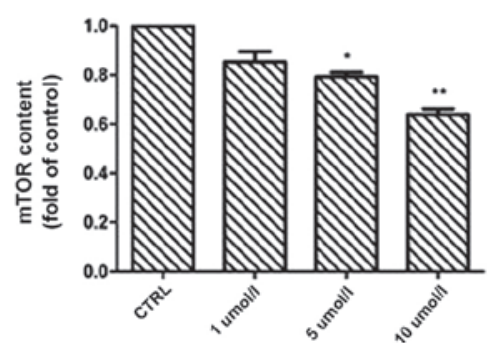

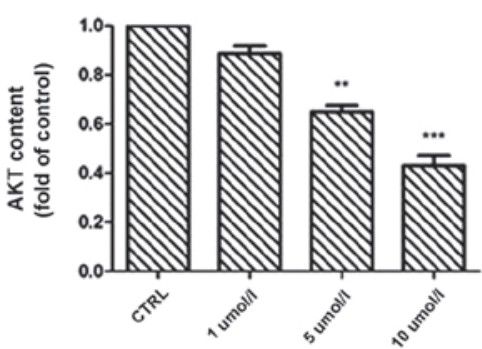

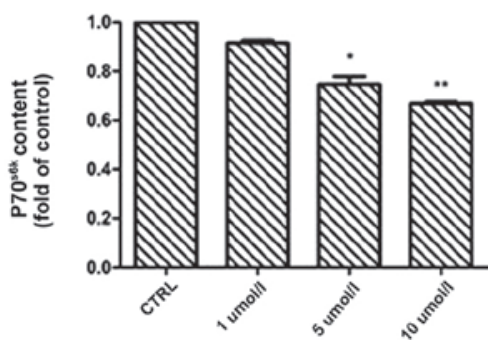

Figure 6. Effect of $\beta$-HIVS treatment on PI3K, Akt, mTOR and P70 ${ }^{\mathrm{S} 6 \mathrm{~K}}$ protein expression in HeLa cells. (A) Western blot analysis of PI3K, Akt, mTOR and $\mathrm{P} 70^{\mathrm{S} 6 \mathrm{~K}}$ expression in HeLa cells subsequent to treatment with $\beta$-HIVS for $48 \mathrm{~h}$. (B) Quantitative analysis of the blots. ${ }^{* * *} \mathrm{P}<0.001$ vs. control group; ${ }^{* *} \mathrm{P}<0.01$ vs. control group; "P<0.05 vs. control group. $\beta$-HIVS, $\beta$-hydroxyisovaleryl-shikonin; PI3K, phosphatidylinositol 3-kinase; AKT, protein kinase B; mTOR, mammalian target of rapamycin; $\mathrm{P} 70^{\mathrm{S} 6 \mathrm{~K}}, 70-\mathrm{kD}$ a ribosomal protein $\mathrm{S} 6$ kinase.

the expression of PI3K, AKT, mTOR and P70S6K was reduced. Compared with the control group, the expression of PI3K in the $10 \mu \mathrm{M}$ group, AKT in the 1,5 and $10 \mu \mathrm{M}$ groups and mTOR in the $10 \mu \mathrm{M}$ group was significantly decreased $(\mathrm{P}<0.001)$, and the expression of mTOR in the $5 \mu \mathrm{M}$ group and $\mathrm{P} 70^{\mathrm{S} 6 \mathrm{~K}}$ in the 5 and $10 \mu \mathrm{M}$ groups was also significantly decreased ( $\mathrm{P}<0.05$; Fig. 6).

\section{Discussion}

PI3K is a lipid kinase that regulates diverse cellular processes, including the proliferation, adhesion, survival, differentiation, apoptosis and motility of cells, and exerts effects by activating AKT (17). Activated AKT contributes to cell proliferation, the inhibition of apoptosis, cell cycle regulation, the promotion of angiogenesis and chemotherapy resistance by triggering downstream signaling, which results in the development and progression of tumors $(18,19)$.

mTOR is an atypical serine/threonine protein kinase, with a molecular weight of $289 \mathrm{kDa}(20-22)$, that acts as a downstream substrate of AKT in the PI3K/AKT pathway (20-22). AKT activates mTOR by phosphorylation at serine 2,448 to improve the efficiency of mRNA translation, 
increase the expression of a series of cell proliferation and differentiation-associated proteins, and promote tumor development and progression (23). Insulin-like growth factor, nerve growth factor and platelet-derived growth factor mediate and promote cell survival through various pathways, and are important anti-apoptotic factors $(18,24)$.

Welker et al (25) previously indicated that, through the $\mathrm{PI} 3 \mathrm{~K} / \mathrm{AKT} / \mathrm{mTOR}$ signaling pathway, activated AKT activates mTOR and regulates two downstream factors, consisting of eukaryotic initiation factor 4E binding protein 1 and ribosomal S6 protein kinase 1, in addition to controlling the translation of proteins for cell proliferation and transformation. S6 protein kinase 1 and $4 \mathrm{E}$ binding protein 1 demonstrate positive and negative regulatory effects on cell proliferation, respectively.

Gao et al (26) verified that the activated PI3K/AKT/mTOR signaling pathway upregulates the expression of cyclin and cyclin-dependent kinase 4 through $\mathrm{P} 70^{\mathrm{S} 6 \mathrm{~K}}$, promoting G1 progression, accelerating the cell cycle and contributing to tumor progression. AKT activates $\mathrm{P} 70^{\mathrm{S6K}}$, a downstream protein of mTOR, to promote actin filament reconstruction and lead to tumor invasion and metastasis. Therefore, the $\mathrm{PI} 3 \mathrm{~K} / \mathrm{AKT} / \mathrm{mTOR}$ cascade is a major signaling pathway for protein synthesis, and the cascade is involved in cell proliferation, differentiation and apoptosis, and tumor invasion and metastasis $(7,8)$. Phosphatase and tensin homolog is a tumor suppressor that acts as a negative feedback regulator of PI3K/AKT/mTOR signaling and antagonizes PI3K by converting phosphatidylinositol-3,4,5-trisphosphate (PIP3) back to phosphatidylinositol-4,5-bisphosphate by dephosphorylation of PIP3 at the 3' position of the inositol ring. This negatively regulates the activity of PI3K and downstream AKT/mTOR signaling, thus inhibiting tumor growth (27).

It is important to identify the molecular targets of natural antitumor drugs and to study the antitumor mechanism of these agents. The root of Lithospermum erythrorhizon (12), also termed arnebia, is a perennial herb that contains complex chemical components. Diverse natural shikonin-like compounds are derived from arnebia roots using various methods. Natural shikonin-like compounds and the derivatives of these compounds demonstrate cytotoxic actions and antitumor effects. $\beta$-HIVS is a shikonin derivative that suppresses tumor cell proliferation and induces tumor cell apoptosis $(28,29)$. Hashimoto et al $(30)$ confirmed that $\beta$-HIVS exerts cytotoxic effects on numerous types of human carcinoma cell lines. When $10^{-6} \mathrm{M} \beta$-HIVS was used to treat HL-60 cells for $3 \mathrm{~h}$, typical apoptotic characteristics were observed in the cells, including morphological changes, nuclear fragmentation, DNA ladder formation and caspase-3 activation, which indicates that $\beta$-HIVS induced tumor cell apoptosis through a caspase-3-dependent mechanism. Previous studies $(28,31)$ verified that $\beta$-HIVS exerted inhibitory and proapoptotic effects on endometrial cancer, chorionic carcinoma and ovarian cancer cells, with $\mathrm{IC}_{50}$ values ranging between $10^{-6}$ and $10^{-8} \mathrm{M}$.

Furthermore, numerous studies have revealed that $\beta$-HIVS is a selective inhibitor of topoisomerase I and an ATP non-competitive inhibitor of protein tyrosine kinases (32-35). $\beta$-HIVS regulates the cell cycle and apoptosis-associated protein activity by inhibiting the activity of epidermal growth factor receptor, decreasing dUTP nucleotidohydrolase activity and suppressing vascular endothelial growth factor receptor activity (36). $\beta$-HIVS has also been revealed to inhibit tumor cell proliferation (35). Overall, there are various antitumor targets of $\beta$-HIVS with complicated mechanisms of action, including cell proliferation, apoptosis and signal transduction $(16,34)$. Few studies have assessed the effect of $\beta$-HIVS on cervical cancer or the signal transduction pathway involved in mediating tumor cell apoptosis.

The present study used MTT assays to detect the effects of various concentrations of $\beta$-HIVS on human cervical cancer HeLa cell proliferation at various time-points. The results demonstrated that $\beta$-HIVS exerted significant inhibitory effects on HeLa cell proliferation. In addition, with an increased $\beta$-HIVS concentration and prolonged treatment time, the inhibitory effects increased in a time- and dose-dependent manner. Tumor occurrence is not only associated with abnormal cell proliferation, but is also strongly correlated with abnormal apoptosis (37). Antitumor drugs used in the clinic exert their effects mainly by inducing tumor cell necrosis and apoptosis (38). In the present study, an increased concentration of $\beta$-HIVS resulted in notable alterations in the number and structure of apoptotic HeLa cells, with a gradual increase in the apoptotic rate. Treatment with $10 \mu \mathrm{M} \beta$-HIVS resulted in evident changes in cell morphology. The proportion of apoptotic cells gradually increased, and late apoptotic changes were observed, including chromatin condensation, nuclear fragmentation, punctiform or lobulated nuclei, intact membrane and membrane blebbing, with the presence of programmed cell death. Flow cytometry revealed that the apoptotic rate of HeLa cells evidently increased subsequent to treatment with $\beta$-HIVS, indicating that $\beta$-HIVS suppressed HeLa cell proliferation by inducing tumor cell apoptosis.

Therefore, the present study investigated the signal transduction pathways that are activated by $\beta$-HIVS to result in the apoptosis of HeLa cells. The PI3K/AKT/mTOR signaling pathway plays an important role in tumor development and progression (9). Activation of this pathway is a key index for the evaluation of the therapeutic effects of treatments and patient prognosis (9). Thus, methods of inhibiting this signaling pathway have been a focus in tumor prevention and molecular-targeted therapy. The results from the present study confirmed that $\beta$-HIVS exerts time- and concentration-dependent effects on PI3K, AKT, mTOR and $\mathrm{P} 70^{\mathrm{S} 6 \mathrm{~K}}$ protein expression. The administration of a high concentration of $\beta$-HIVS and a prolonged treatment time resulted in an evident decrease in the expression of PI3K, AKT, mTOR and P70 ${ }^{\mathrm{S} 6 \mathrm{~K}}$. Therefore, the present study hypothesized that the molecular mechanism of the $\beta$-HIVS-mediated inhibition of HeLa cell proliferation and promotion of apoptosis was as follows. $\beta$-HIVS suppresses the activity of PI3K, downregulates $\mathrm{PI} 3 \mathrm{~K}$ protein expression, regulates the AKT protein and the downstream target of AKT mTOR, and also regulates $\mathrm{P} 70^{\mathrm{S} 6 \mathrm{~K}}$ expression levels, which results in the inhibition of HeLa cell proliferation. Thus, this demonstrates the potential clinical value of $\beta$-HIVS.

In the present study, flow cytometry demonstrated that $\beta$-HIVS elevated the apoptotic rate of HeLa cells, which was strongly associated with the concentration of $\beta$-HIVS. Simultaneously, $\beta$-HIVS altered the proliferation cycle of HeLa cells, resulting in a reduced proportion of cells in the $G_{0} / G_{1}$ phase, increased proportion of cells in the $\mathrm{S}$ phase and no evident 
change in the proportion of $\mathrm{G}_{2} / \mathrm{M}$ cells, in addition to cell cycle blockage in the $\mathrm{S}$ phase. Overall, $\beta$-HIVS interfered with the cell cycle and then suppressed tumor growth. Therefore, if $\beta$-HIVS is combined with agents that target different phases of the cell cycle in the clinic, chemotherapy resistance may be avoided.

The current study primarily explored the molecular mechanism of $\beta$-HIVS on the induction of apoptosis in HeLa cells. $\beta$-HIVS may inhibit tumor cell proliferation and increase the apoptotic rate of tumor cells. In the current study, $\beta$-HIVS promoted tumor cell apoptosis and exerted antitumor effects, possibly by inhibiting the $\mathrm{PI} 3 \mathrm{~K} / \mathrm{AKT} / \mathrm{mTOR}$ signaling pathway and affecting various downstream effector molecules in this cascade. However, the involvement of other molecular pathways and the association between these pathways remains poorly understood (39). Numerous factors affect tumor cell apoptosis, and regulation of apoptosis is complicated (40). Thus, on the basis of these in vitro findings regarding the PI3K/AKT/mTOR signaling pathway, if the effects of $\beta$-HIVS on cervical cancer are studied in vivo and the consistency of the in vivo and in vitro experimental results is evaluated, a deeper understanding of the occurrence, development, treatment and prognosis of cervical cancer may be acquired. In addition, the present data revealed that $\beta$-HIVS suppressed HeLa cell proliferation, induced tumor cell apoptosis and interfered with the cell cycle of tumor cells, highlighting the potential of $\beta$-HIVS as a novel high-performance non-toxic antitumor agent. Blockade of the PI3K/AKT/mTOR signaling pathway may effectively suppress tumor cell proliferation and promote tumor cell apoptosis, which would be a novel strategy for molecular-targeted therapy of cervical cancer.

\section{Acknowledgements}

This study was supported by the Jiangsu Provincial Department of Science and Technology Social Development Project in China (grant no. BS2006536) Jiangsu Provincial Higher Learning Institute Postgraduate Science Research Innovation Project in China (grant no. CXZZ13-0918).

\section{References}

1. Parkin DM, Bray F, Ferlay J and Pisani P: Global cancer statistics, 2002. CA Cancer J Clin 55: 74-108, 2005.

2. Roque DR, Wysham WZ and Soper JT: The surgical management of cervical cancer: An overview and literature review. Obstet Gynecol Surv 69: 426-441,2014.

3. World Health Organization: Diagnosis and treatment of invasive cervical cancer. In: Comprehensive Cervical Cancer Control: A Guide to Essential Practice. 2nd edition. World Health Organization, Geneva, pp153-175, 2014.

4. Mabuchi S, Kuroda H, Takahashi R and Sasano T: The $\mathrm{PI} 3 \mathrm{~K} / \mathrm{AKT} / \mathrm{mTOR}$ pathway as a therapeutic target in ovarian cancer. Gynecol Oncol 137: 173-179, 2015.

5. Eskander RN and Tewari KS: Exploiting the therapeutic potential of the PI3K-AKT-mTOR pathway in enriched populations of gynecologic malignancies. Expert Rev Clin Pharmacol 7: 847-858, 2014

6. Cho DC: Targeting the PI3K/Akt/mTOR pathway in malignancy: Rationale and clinical outlook. BioDrugs 28: 373-381, 2014.

7. Han Z, Wu K, Shen H, Li C, Han S, Hong L, Shi Y, Liu N, Guo C, Xue Y, et al: Akt1/protein kinase B alpha is involved in gastric cancer progression and cell proliferation. Dig Dis Sci 53: 1801-1810, 2008.
8. Samuels Y and Ericson K: Oncogenic PI3K and its role in cancer. Curr Opin Oncol 18: 77-82, 2006.

9. Wu J, Chen $\mathrm{C}$ and Zhao KN: Phosphatidylinositol 3-kinase signaling as a therapeutic target for cervical cancer. Curr Cancer Drug Targets 13: 143-156, 2013.

10. Tanaka S, Tajima M, Tsukada M and Tabata M: A comparative study on anti-inflammatory activities of the enantiomers, shikonin and alkannin. J Nat Prod 49: 466-469, 1986.

11. Mao X, Yu CR, Li WH and Li WX: Induction of apoptosis by shikonin through a ROS/JNK-mediated process in Bcr/Abl-positive chronic myelogenous leukemia (CML) cells. Cell Res 18: 879-888, 2008.

12. Andújar I, Ríos JL, Giner RM and Recio MC: Pharmacological properties of shikonin - a review of literature since 2002. Planta Med 79: 1685-1697, 2013.

13. Andújar I, Recio MC, Giner RM and Ríos JL: Traditional chinese medicine remedy to jury: The pharmacological basis for the use of shikonin as an anticancer therapy. Curr Med Chem 20: 2892-2898, 2013

14. Lu JJ, Bao JL, Wu GS, Xu WS, Huang MQ, Chen XP and Wang YT: Quinones derived from plant secondary metabolites as anti-cancer agents. Anticancer Agents Med Chem 133: 456-463, 2013.

15. Wang R, Yin R, Zhou W, Xu D and Li S: Shikonin and its derivatives: A patent review. Expert Opin Ther Pat 22: 977-997, 2012.

16. Rajasekar S, Park da J, Park C, Park S, Park YH, Kim ST, Choi $\mathrm{YH}$ and Choi YW: In vitro and in vivo anticancer effects of Lithospermum erythrorhizon extract on B16F10 murine melanoma. J Ethnopharmacol 144: 335-345, 2012.

17. Yuan TL and Cantley LC: PI3K pathway alterations in cancer: Variations on a theme. Oncogene 27: 5497-5510, 2008.

18. Song G, Ouyang G and Bao S: The activation of Akt/PKB signaling pathway and cell survival. J Cell Mol Med 9: 59-71, 2005.

19. Martelli AM, Evangelisti C, Chiarini F and McCubrey JA: The phosphatidylinositol 3-kinase/Akt/mTOR signaling network as a therapeutic target in acute myelogenous leukemia patients. Oncotarget 1: 89-103, 2010 .

20. Sarbassov DD, Guertin DA, Ali SM and Sabatini DM: Phosphorylation and regulation of Akt/PKB by the rictor-mTOR complex. Science 307: 1098-1101, 2005.

21. Martelli AM,Evangelisti C,Chiarini F, Grimaldi C, Cappellini A, Ognibene A and McCubrey JA: The emerging role of the phosphatidylinositol 3-kinase/Akt/mammalian target of rapamycin signaling network in normal myelopoiesis and leukemogenesis. Biochim Biophys Acta 1803: 991-1002, 2010.

22. Aimbetov R, Chen CH, Bulgakova O, Abetov D, Bissenbaev AK, Bersimbaev RI and Sarbassov DD: Integrity of mTORC2 is dependent on the rictor Gly-934 site. Oncogene 31: 2115-2120, 2012.

23. Huang S and Houghton PJ: Targeting mTOR signaling for cancer therapy. Curr Opin Pharmacol 3: 371-377, 2003.

24. Xu G, Zhang W, Bertram P, Zheng XF and McLeod H: Pharmacogenomic profiling of the PI3K/PTEN-AKT-mTOR pathway in common human tumors. Int J Oncol 24: 893-900, 2004.

25. Welker ME and Kulik G: Recent syntheses of PI3K/Akt/mTOR signaling pathway inhibitors. Bioorg Med Chem 21: 4063-4091, 2013.

26. Gao N, Flynn DC, Zhang Z, Zhong XS, Walker V, Liu KJ, Shi X and Jiang BH: G1 cell cycle progression and the expression of G1 cyclins are regulated by $\mathrm{PI} 3 \mathrm{~K} / \mathrm{AKT} / \mathrm{mTOR} / \mathrm{p} 70 \mathrm{~S} 6 \mathrm{~K} 1$ signaling in human ovarian cancer cells. Am J Physiol Cell Physiol 287: C281-C291, 2004.

27. Hay N and Sonenberg N: Upstream and downstream of mTOR. Genes Dev 18: 1926-1945, 2004.

28. Takai N, Ueda T, Nishida M, Nasu K and Narahara $H$ : Beta-hydroxyisovalerylshikonin has a profound anti-growth activity in human endometrial and ovarian cancer cells. Gynecol Oncol 109: 107-114, 2008

29. Rao Z, Liu X, Zhou W, Yi J and Li SS: Synthesis and antitumour activity of $\beta$-hydroxyisovalerylshikonin analogues. Eur J Med Chem 46: 3934-3941, 2011

30. Hashimoto S, Xu M, Masuda Y, Aiuchi T, Nakajo S, Cao J, Miyakoshi M, Ida Y, Nakaya K and Hashimoto S: Beta-hydroxyisovalerylshikonin inhibits the cell growth of various cancer cell lines and induces apoptosis in leukemia HL-60 cells through a mechanism different from those of Fas and etoposide. J Biochem 125: 17-23, 1999. 
31. Takai N, Ueda T, Nishida M, Nasu $K$ and Narahara $H$ : Anti-neoplastic effect of $\beta$-hydroxyisovalerylshikonin on a human choriocarcinoma cell line. Mol Med Rep 3: 515-518, 2010.

32. Nakaya $\mathrm{K}$ and Miyasaka T: A shikonin derivative beta-hydroxyisovalerylshikonin, is an ATP-non-competitive inhibitor of protein tyrosine kinases. Anticancer Drugs 14: 683-693, 2003.

33. Hashimoto S, Xu Y, Masuda Y, Aiuchi T, Nakajo S, Uehara Y, ShibuyaM,YamoriTandNakayaK:Beta-hydroxyisovalerylshikonin is a novel and potent inhibitor of protein tyrosine kinases. Jpn J Cancer Res 93: 944-951, 2002.

34. Kajimoto S, Horie M, Manabe H, Masuda Y, Shibayama-Imazu T, Nakajo S, Gong XF, Obama T, Itabe $\mathrm{H}$ and Nakaya K: A tyrosine kinase inhibitor, beta-hydroxyisovalerylshikonin, induced apoptosis in human lung cancer DMS114 cells through reduction of dUTP nucleotidohydrolase activity. Biochim Biophys Acta 1782: 41-50, 2008.

35. Komi Y, Suzuki Y, Shimamura M, Kajimoto S, Nakajo S, Masuda M, Shibuya M, Itabe H, Shimokado K, Oettgen P, et al: Mechanism of inhibition of tumor angiogenesis by beta-hydroxyisovalerylshikonin. Cancer Sci 100: 269-277, 2009.
36. Nishida M, Nasu K, Ueda T, Yuge A, Takai N and Narahara $\mathrm{H}$ Beta-hydroxyisovalerylshikonin induces apoptosis and G0/G1 cell-cycle arrest of endometriotic stromal cells: A preliminary in vitro study. Hum Reprod 21: 2850-2856, 2006.

37. Boroughs LK and DeBerardinis RJ: Metabolic pathways promoting cancer cell survival and growth. Nat Cell Biol 17: 351-359, 2015.

38. Castro J, Ribó M, Benito A and Vilanova M: Mini-review: Nucleus-targeted ribonucleases as antitumor drugs. Curr Med Chem 20: 1225-1231, 2013.

39. Jin FP and Zhang M: Progress of experimental researches on Chinese herbal compounds for inducing tumor cell apoptosis. Chin J Integr Med 16: 565-571, 2010.

40. Zhao X, Ai M, Guo Y,Zhou X, Wang L, Li X and Yao C: Poly I: C-induced tumor cell apoptosis mediated by pattern-recognition receptors. Cancer Biother Radiopharm 27: 530-534, 2012. 